\title{
Sonoma State University's North Bay Historic Preservation Digital Collection: Starting a Digital Project
}

\section{Lynn Prime}

Lynn Prime (primel@sonoma.edu) is the digital projects librarian in the Sonoma State University Library's regional and special collections department

\section{The discovery}

A number of years ago, a staff member in the Sonoma State University (SSU) Library's regional and special collections department discovered a box of mounted photographs and accompanying display material of Sonoma County sites. A bit of detective work led to further identification of these photos as part of a larger compilation of materials associated with History 362, a course offered at SSU in the mid-1970s. More recently, additional materials were connected to this original discovery, including photo negatives, proof sheets, and some slides; a dozen audiotaped interviews of Sonoma County residents; student papers on the architectural styles of buildings in the county; resource inventories of historic county sites; and files from the offices of two history professors who were involved in the work to create these documents. And History 362 wasn't the only course with which various documents were associated. The organization of materials continues to this day, but the regional and special collections department staff has managed to piece together most of the history of this unique collection.

\section{Background}

In 1972, Professor Timothy Bell in the then-Sonoma State College geography department worked with the Sonoma County Planning Department to initiate a systematic survey of sites and buildings throughout the county. This survey was led by Sonoma State students, but the county provided official assistance in the form of maps and direction. Students surveyed more than 300 sites and structures to be considered for historic preservation. The plan was that the Sonoma County Site Survey would be the basis
Figure 1. Sonoma State University historic preservation course announcement

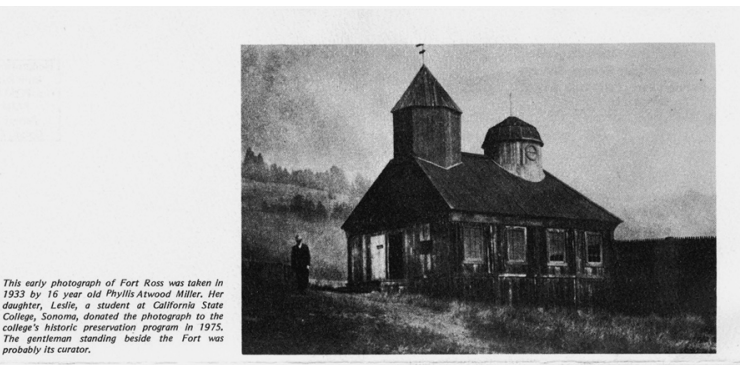

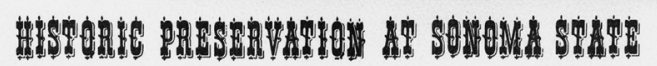

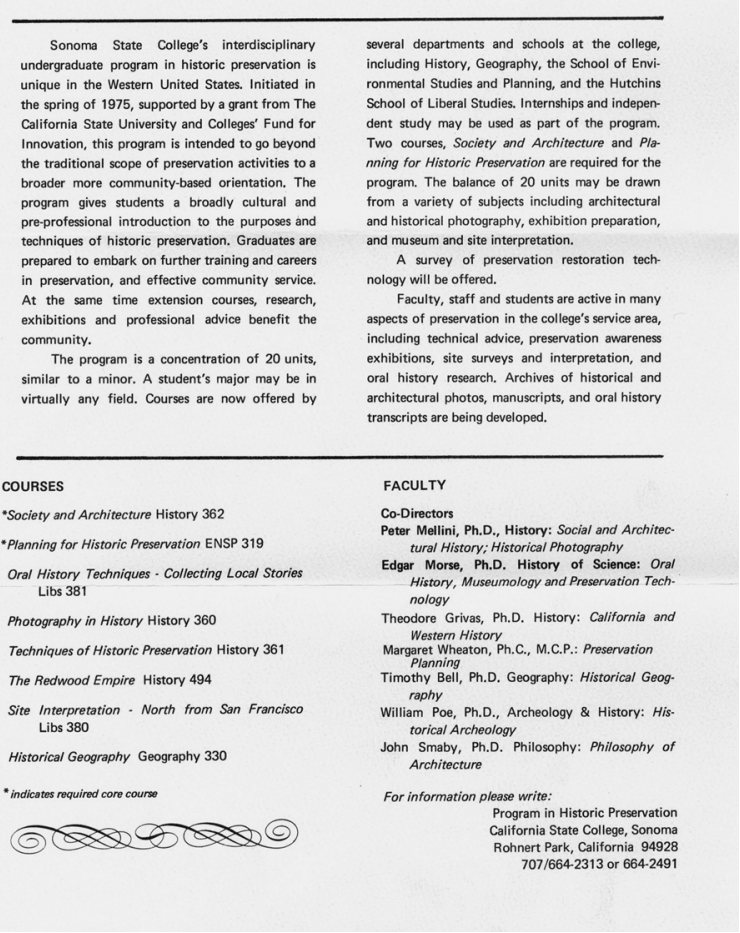

for the formation of the Sonoma County Historic Landmarks Commission.

This initial effort provided guidance for the development over the next number of years of Sonoma State College history courses on local historic sites. In 1974, the history department began to provide its majors and other interested students with practical experience in local history and historical photography through courses within the department. In addi- 
Figure 2 North Bay Historic Preservation Digital Collection survey announcement

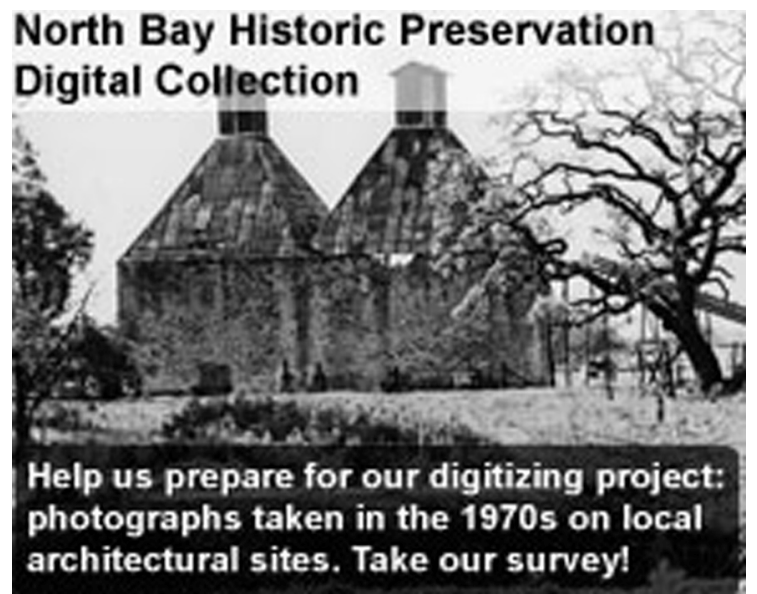

tion, the department offered courses such as Methods in Local History, Quantitative Methods and Historical Research, and Archaeological Theory and Practice.

The next year, the college began a new undergraduate program in historic preservation. One of the courses in the program was Photography in History, a course that involved collecting old and new photographs of Sonoma County's past and (at that time) present. Unfortunately, that program lasted only a few years.

Professor Edgar Morse launched an oral history project for undergraduates during this same period, a project to record and preserve people's memories of Sonoma County from the 1850 s to the 1970s. Professor Peter Mellini, now retired, was a co-director of the program, and was the library's initial contact in 2009 as we began to make plans to digitize the images and establish a new digital collection of these valuable local resources.

The work of these professors and their students culminated in the creation of the Sonoma County Preservation Project, now housed in the library's regional and special collections department and still being added to. More than 800 photographs taken in the 1970s have been digitized and are being made available to the public as the North Bay Historic Preservation Digital Collection. ${ }^{1}$

\section{Process}

The California State Library awarded our library a Local History Digital Resources Project (LHDRP) grant of $\$ 5,000$ in July 2009. Our procedures for digitization were already partly under way: earlier in 2009, we had begun to determine permissions issues with the images, taken by more than 50 student photographers. We had created and distributed a survey assessing people's interest in what the collection had to offer We had established a metadata spreadsheet with basic information we wanted to include with each digital object. And we had created a scanning procedural for our student assistants, who did the bulk of the scanning work for the project.

With the grant in hand, the scramble began - to choose the first 200 images we wanted to highlight in our image debut on the Online Archive of California, ${ }^{2}$ ship them out in batches for scanning by a professional digital imaging company, finalize metadata for the images, incorporating the California Digital Library's use of Dublin Core metadata standards, and upload images and metadata - first into our library's North Bay Digital Collections and then into the Online Archive of California.

The one-year grant required us to attend six information and training sessions sponsored by the California State Library and Califa, ${ }^{3}$ and to prepare six-month narrative and quarterly budget reports detailing our efforts. Although time-consuming, this work gave us an opportunity to collaborate with more-experienced people who could guide us through the process and to learn from other grant winners with fledgling projects.

\section{Questions we pondered: choices, organization, publicity}

\section{Choices}

The initial decision about what photos to digitize ended up shaping our entire digital collection and the final organization of the physical collection of Sonoma County Preservation Project photographs.

Our procedure for choosing the images to debut this new digital collection included an evaluation of what local sites were already represented quite thoroughly in images in Sonoma County: the Luther Burbank Home and Gardens, the McDonald Mansion, the Comstock Mansion. We focused instead on more common buildings, including residences and commercial buildings, or buildings that reflected a particularly noteworthy architectural style. We attempted to represent a range of North Bay communi- 
Figure 3. Santa Rosa, California railroad station, ca. 1975, CJanet Silber

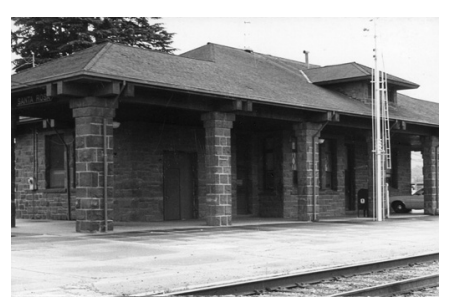

ties, from the county seat to the resort communities along the Russian River, and to highlight unusual history, such as the stories of county schoolhouses Including the Potter School in Bodega, made famous by Alfred Hitchcock's movie "The Birds" and the visual history of railroad buildings throughout the county. We tried to gauge what kinds of historic North Bay sites would be of interest to students and faculty in the university's many departments, as well as to county historians. And we focused at the start more on images by photographers from whom we had already garnered permission for digitization or by anonymous photographers.

\section{Organization}

The original images were organized by geographic area a number of years ago, indexed, and housed in labeled archival boxes separated by buffered paper. As a result of the grant, however, we ended up reorganizing the material by numbers created for the scanned images, so the first 200 scanned images became numbers 1-200 (carpssu_001 through carpssu_ 200) in our new numbering system. Although not always ideal for researchers, this organization necessitated only a cross-reference from the original identifiers to the digitized image identifiers to make it useful. We will flesh out some of the geographic cross-references a bit more thoroughly as part of our reorganization. In addition, we worked to make keyword access to the digital images as strong as possible, with the original photograph index continuing to serve as the ultimate record of the entire physical collection.

\section{Publicity}

With the help of our graphics and publicity staff, we focused on creating a brochure announcing our newest digital collection. ${ }^{4}$ This brochure was ulti-
Figure 4 Beltane Ranch, Sonoma, California, ca. 1975, (CLeslie Miller

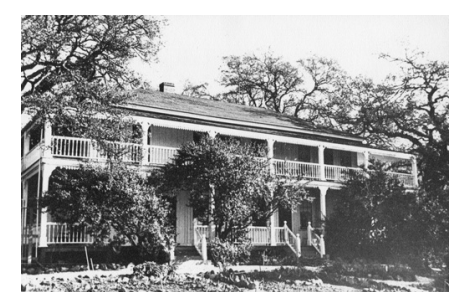

mately mailed out to close to 1,000 individuals and institutions involved in the archives, historical society, and library worlds. Our web services librarian created numerous Twitter announcements about our collection and its digitized photos, and our department began a blog (News from North Bay Digital Collections) to highlight some of these images. ${ }^{5} \mathrm{We}$ hope to publicize photos more broadly on photosharing sites such as Flickr to encourage use of our digital collections, and to remind our own students, staff, and faculty of the amazing array of digitized resources available to them for their research.

A number of venues have taken an interest in our new collection. The SSU News Center has written about it, and the county newspaper, the Press Democrat, has used its Arts Blog to highlight the collection's many mystery photos. ${ }^{6}$ The same local paper plans to publish a Sunday feature highlighting interviews with county residents who have personal stories about some of the photographed sites.

\section{And now what?}

In our dreams (and dreams sometimes do come true), our library would initiate some of these programs:

- Oral interviews conducted by SSU students that would reflect more of the history of some of these sites.

- Photographic documentation of the collection's buildings as they appear in the early $21^{\text {st }}$ century, in order to compile a visual record of the changes to them over time. This would help keep the collection vibrant and accessible in the future.

- Mapping of GPS coordinates that would visually establish image location.

- Collaboration with local historical societies to include links to their information relative to the 
images, as well as to flesh out some of the descriptive metadata for our collection.

Time will tell how and whether these programs become a reality, but there are definite possibilities for an even more complete chronicling of North Bay historic sites.

\section{In the meantime}

With the help of Google Analytics, we are tracking use of the new digital collection. Although our gains in use are modest, they continue upward with each jot of publicity we receive. Our digital collections have already garnered interest from New York, Osaka, and Los Angeles, and have resulted in increased use of our physical collections. Although the interest in what our collections offer the student and researcher definitely affects our department's part-time staff of two librarians, we're pleased that some of the small hidden collections we have inventoried are receiving more recognition.

During 2011, we plan to finish creating the metadata, scanning the remaining 500 or so images, and adding those images to the collection of almost 300 we currently have available for the public to access.
As our unique digital collections expand, we hope to increase their visibility by making our metadata accessible through WorldCat and making even more of both our metadata and images available on the Online Archive of California.

\section{Endnotes}

1 North Bay Historic Preservation Digital Collection, http:// northbaydigital.sonoma.edu/. The collection is powered by OCLC's CONTENTdm ${ }^{\circledR}$ digital asset management software and is supported in part by the U.S. Institute of Museum and Library Services under the provisions of the Library Services and Technology Act, administered in California by the State Librarian.

2 Online Archive of California, http://www.oac.cdlib.org/.

3 Califa Group, http://www.califa.org/aboutlhdrp.php.

4 North Bay Historic Preservation Digital Collection brochure, http://library.sonoma.edu/regional/historicalpreservation collection.pdf.

5 News from North Bay Digital Collections, http://reference. sonoma.edu/northbayregional/.

6 Sonoma State University News Center, "New SSU Digital Collection Opens Doors to North Bay History," July 29, 2010, http://www.sonoma.edu/newscenter/2010/07/new-ssudigital-collection-opens-doors-to-north-bay-history.html; and Dan Taylor, "Share Your Local Lore," Press Democrat Arts Blog, http://arts.blogs.pressdemocrat.com/category/history/. Introduction 